\title{
On the Skin of a Doll
}

\author{
Diana Thorneycroft
}

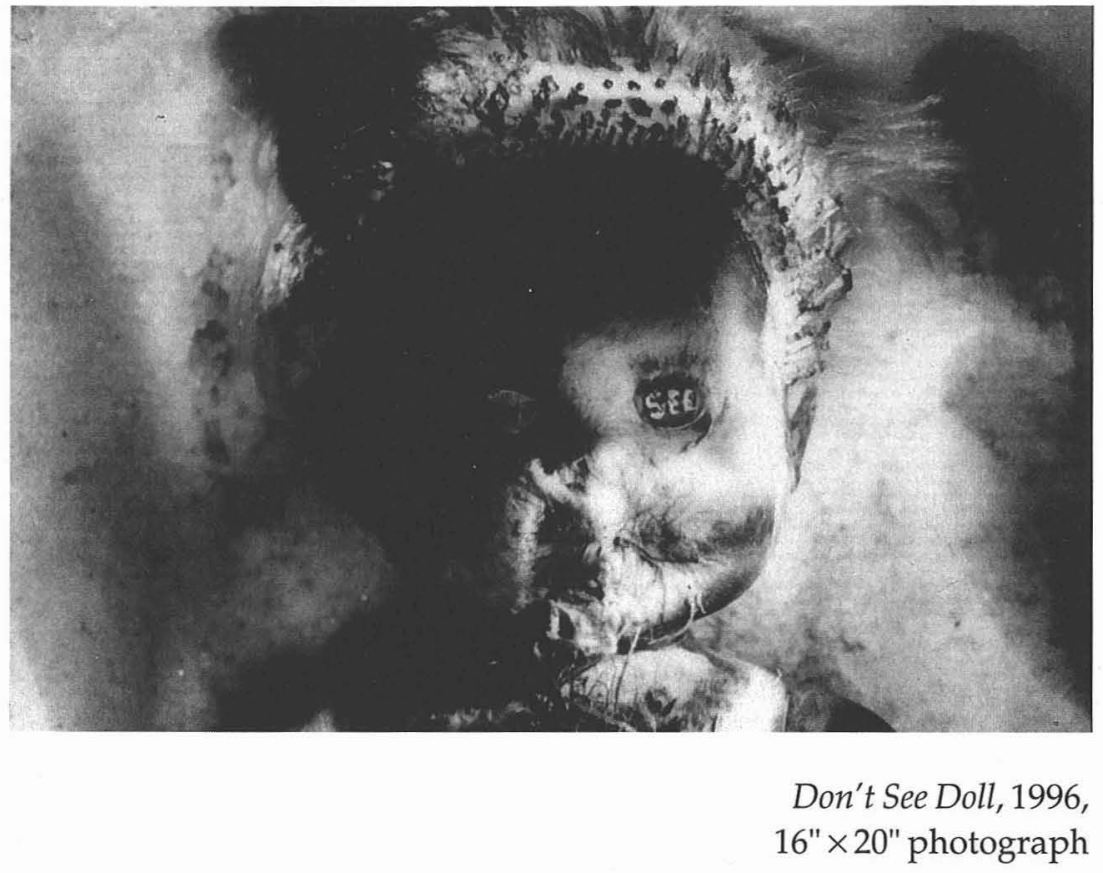


On the Skin of a Doll $\cdot 31$

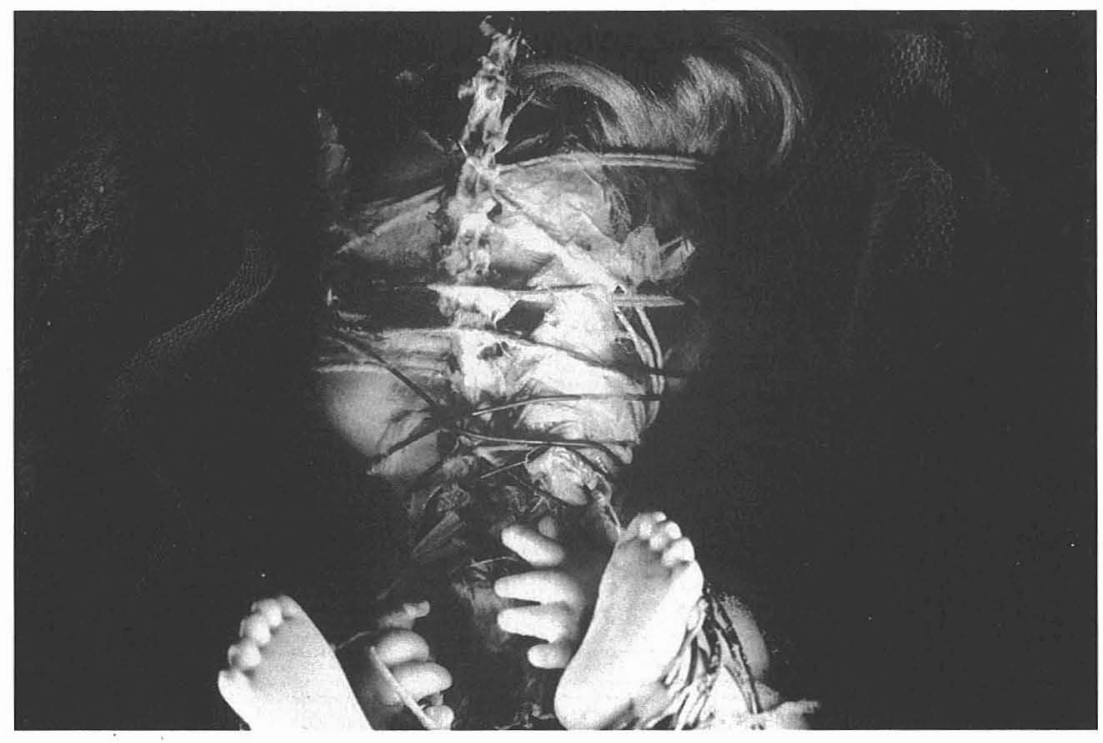

Bone Cunt Doll, 1996, $16 " \times 20 "$ photograph 


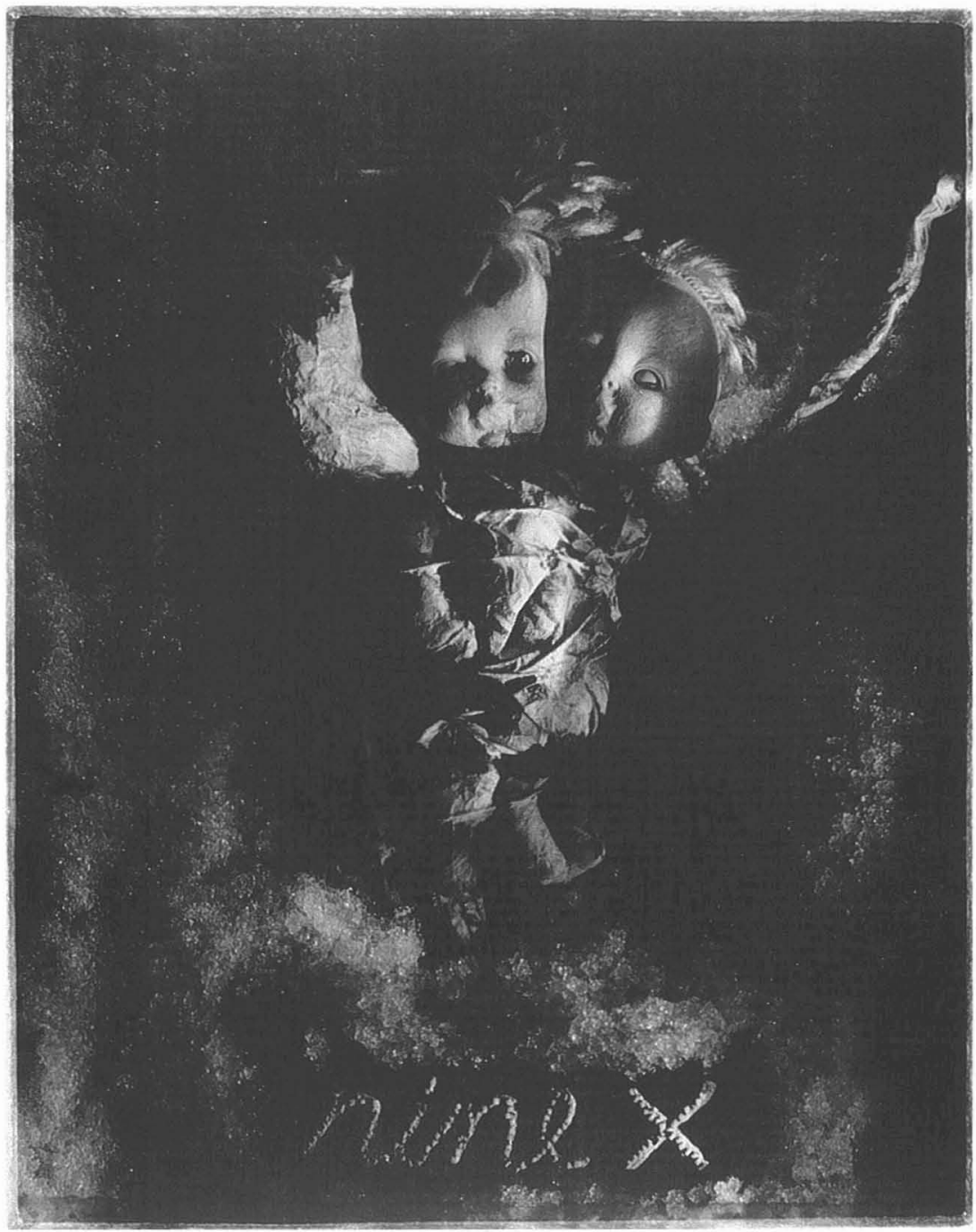

Twins Before Fire, 1996, $16^{\prime \prime} \times 20$ " photograph 
On the Skin of a Doll $\cdot 33$

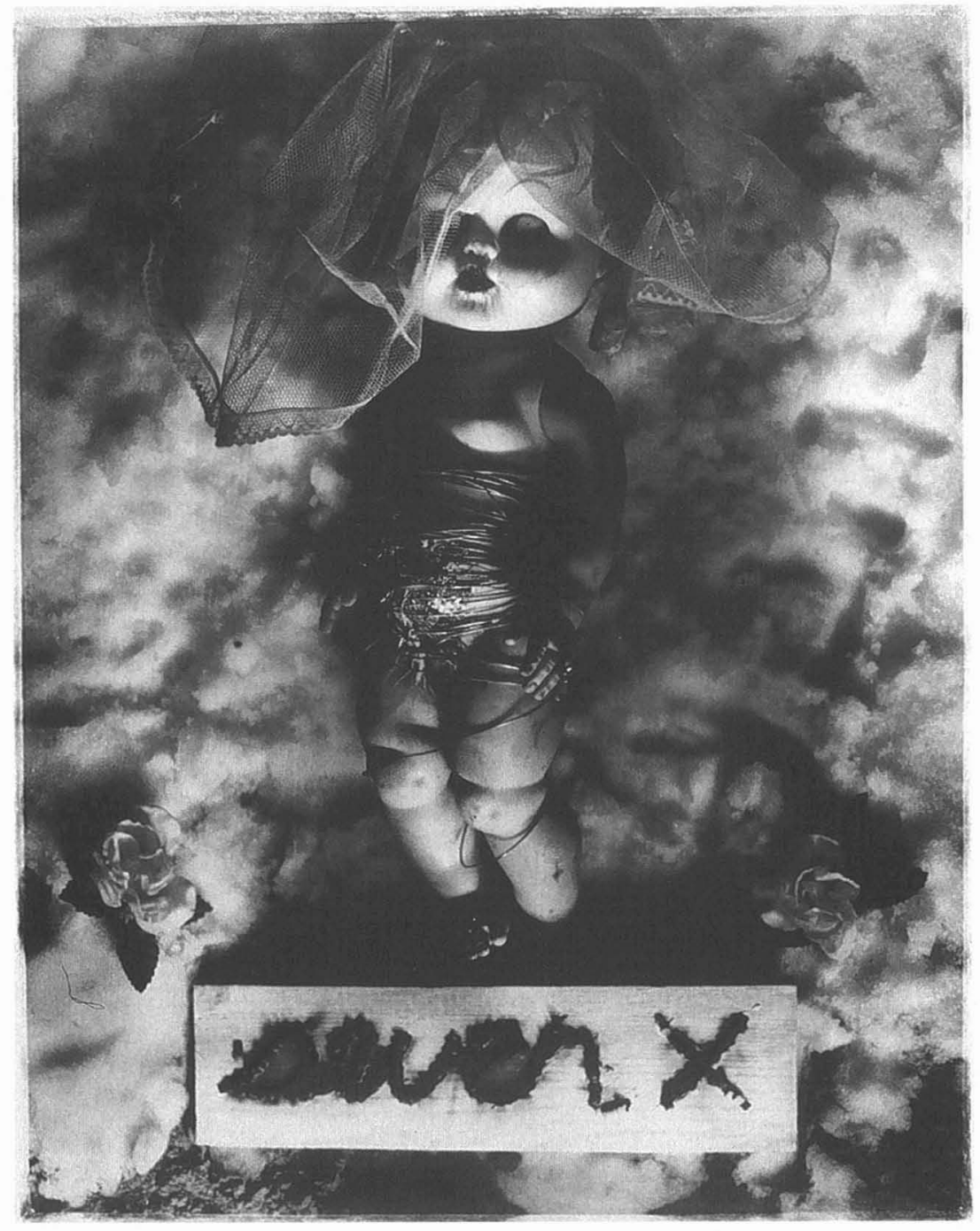

Bride Doll, 1996, $16 " \times 20 "$ photograph 